\title{
Health Care Costs and Thromboembolic Events in Hydroxyurea-Treated Patients with Polycythemia Vera
}

\author{
Shreekant V. Parasuraman, BPharm, PhD; Nianwen Shi, PhD; \\ Dilan C. Paranagama, PhD; and Machaon Bonafede, PhD, MPH
}

\begin{abstract}
BACKGROUND: Patients with polycythemia vera (PV) are at increased risk of thromboembolic events (TEs), which are key contributors to reduced overall survival compared with the age- and sex-matched general population. In addition to aspirin and phlebotomy to maintain hematocrit level $<45 \%$, many patients receive cytoreduction with hydroxyurea (HU), which is associated with improved survival and may reduce the risk of cardiovascular events and TEs. However, 1 in 4 patients become resistant to or intolerant of HU. In the general population, prophylaxis and treatment following arterial and venous thromboses are associated with increased health care resource utilization and costs.
\end{abstract}

OBJECTIVE: To describe the health care resource utilization and costs associated with TEs in patients with PV treated with HU in the United States.

METHODS: This retrospective cross-sectional analysis of the Truven Health Analytics MarketScan Research Databases included adult patients with a PV diagnosis who were newly treated with $\mathrm{HU}$ and continuously enrolled in medical and pharmacy benefit plans for $\geq 12$ months pre- and post-index. HU treatment administration, persistence, adherence, and related adverse events, as well as TEs, were reported during the 12-month follow-up period. HU treatment patterns were further analyzed in a subgroup analysis comparing patients with and without $\mathrm{a} \geq 45$-day gap in HU treatment. Health care resource utilization and costs were analyzed in a subgroup analysis comparing patients who had TEs in the 12-month follow-up period with those who did not. Tests for statistically significant differences across the comparison groups were conducted, including chi-square tests for categorical variables and t-tests for continuous variables.

RESULTS: The records of 1,322 patients with PV were included in this study. Mean age was 66.0 years; $51.3 \%$ were men; and $14.0 \%$ had a history of TEs. During the first year of HU treatment, 764 (57.8\%) patients had a treatment gap of $\geq 45$ days; however, treatment adherence was similar between those with and those without a gap ( $85.2 \%$ vs. $90.7 \%$, respectively). TEs occurred in $216(16.3 \%)$ patients within 12 months of $\mathrm{HU}$ initiation. Health care resource utilization was higher for patients with TEs versus those without, including the proportion of patients requiring inpatient services $(50.9 \%$ vs. $18.4 \% ; P<0.001)$ and emergency room visits $(48.1 \%$ vs. $26.3 \% ; P<0.001)$ and the mean number of inpatient admissions (1.7 vs. $1.3 ; P=0.004)$; office visits (18.9 vs. $14.1 ; P<0.001$ ); and prescriptions (45.8 vs. $36.2 ; P<0.001$ ). In addition, total mean health care costs $(\$ 45,040$ vs. $\$ 16,438 ; P<0.001)$; inpatient costs $(\$ 18,952$ vs. $\$ 4,794 ; P<0.001)$; outpatient costs $(\$ 20,844$ vs. $\$ 8,046 ; P<0.001)$; and outpatient pharmacy costs $(\$ 5,244$ vs. $\$ 3,598$; $P=0.002$ ) were higher among patients with TEs than those without.

CONCLUSIONS: Patients with PV receiving treatment with HU remain at risk for TEs. The occurrence of TEs during the 12-month follow-up in this patient population was associated with higher health care resource utilization and costs.

J Manag Care Spec Pharm. 2018;24(1):47-55

Copyright $\odot 2018$, Academy of Managed Care Pharmacy. All rights reserved.

\section{What is already known about this subject}

Patients with polycythemia vera (PV) are at increased risk of thromboembolic events (TEs) and mortality.

In the general population, TEs are associated with increased health care resource utilization and costs.

Some patients with PV benefit from the addition of cytoreductive therapy with hydroxyurea (HU); however, 1 in 4 become resistant or intolerant.

\section{What this study adds}

In this retrospective cross-sectional analysis of 1,322 patients with PV, nearly 1 in 6 patients experienced a TE in the first year after the initiation of HU treatment, which supports previous data concerning HU resistance/intolerance and corresponding increased mortality rates

The occurrence of TEs during the 12-month follow-up in this patient population was associated with significantly higher annual health care resource utilization and direct medical costs that represented more than half the median U.S. income.

$\mathrm{P}$ olycythemia vera (PV) is a Philadelphia-negative chronic myeloproliferative neoplasm (MPN) that is primarily characterized by erythrocytosis and constitutively active mutations in Janus kinase 2 (JAK2), ${ }^{1}$ primarily JAK2V617F (95\%-97\%) or exon 12 mutations (2\%-4\%). ${ }^{2-4} \mathrm{PV}$ was estimated to affect 44 to 57 patients per 100,000 individuals in the United States between 2008 and 2010. ${ }^{5}$

Patients with PV have a higher mortality risk compared with the general population, ${ }^{6-8}$ which is primarily driven by thromboembolic events (TEs) and cardiovascular disease. ${ }^{9}$ A retrospective analysis of patients with PV or other MPNs ( $\mathrm{n}=11,155)$ reported that patients with PV have a 5- and 9-fold higher risk of arterial and venous thrombosis, respectively, compared with matched controls for age, sex, and country of residence. ${ }^{10}$ A recent analysis of the MPN registry of the Study Alliance Leukemia reported that although thrombosis and TEs most often occurred among patients with PV and other MPNs around the time of diagnosis, one third of all events occurred after that date. ${ }^{11}$ Deep vein thrombosis and acute coronary syndrome were the most common events among patients with PV. ${ }^{11}$ A separate analysis of patients with PV recruited 
to the large European Collaboration on Low-Dose Aspirin in Polycythemia Vera (ECLAP) study $(n=1,638)$ reported that cardiovascular mortality accounted for $45 \%$ of all deaths (mean follow-up, 2.7 years), with nonfatal thrombotic events occurring in $10.3 \%$ of patients. ${ }^{9}$ Elevated hematocrit $(\geq 45 \%),{ }^{12}$ leukocytosis $(\geq 11 \times 109 / \mathrm{L}),{ }^{13}$ and higher JAK2V617F allele burden (ratio of mutant to wild-type JAK2 in hematopoietic cells; $\geq 75 \%$ ) have been associated with a higher risk of TEs. ${ }^{14}$

In addition to the disease-related clinical burden of $\mathrm{PV}^{15}$ patients carry a greater financial burden compared with age- and sex-matched controls, driven by higher health care resource utilization and associated costs. ${ }^{16} \mathrm{~A}$ large retrospective analysis of insurance claims in the United States reported that patients with PV $(n=5,752)$ had significantly more hospital admissions and physician office visits and significantly longer hospital stays compared with matched controls. ${ }^{16}$ The resulting medical, pharmacy, and total annual costs for patients with PV were almost twice as high as the general population in 2010. ${ }^{16}$

A key contributor to the elevated costs for patients with PV may be TE-related treatments. The annual costs associated with prophylaxis or treatment following an arterial TE in the general population (i.e., not limited to patients with PV) are primarily driven by hospitalization and drug costs and have been estimated to range from approximately $\$ 13,000$ to $\$ 66,000$ (U.S. dollar values $1998-2008),{ }^{17-21}$ with direct hospital-related admission and treatment costs ranging from $\$ 58,000$ to $\$ 115,000$ (U.S. dollar values 2003-2005)..$^{22}$ Following a venous TE, annual direct medical treatment costs in the general population have been estimated to range from $\$ 10,000$ to $\$ 34,000$ (U.S. dollar values 2008-2012). ${ }^{23,24}$

The goals of PV treatment highlight the need to reduce the risk of cardiovascular events and TEs and to alleviate disease-related symptoms. ${ }^{25}$ Treatment with aspirin and maintenance of hematocrit level $<45 \%$ with phlebotomy are associated with reduced risk of cardiovascular events, TEs, and related deaths. ${ }^{12,26}$ Some patients benefit from the addition of cytoreductive therapy, which is often hydroxyurea $(\mathrm{HU})^{27,28}$; however, resistance and intolerance to HU have been documented in $11 \%$ and $13 \%$ of patients with PV treated with HU, respectively. ${ }^{29}$ Patients with HU resistance have higher risks of disease transformation to myelofibrosis and acute myeloid leukemia, along with higher mortality risk. ${ }^{29}$

There is a knowledge gap in the contemporary biomedical literature with regard to the effects of cardiovascular events and TEs on health care costs associated with HU treatment in patients with PV. The objective of this analysis was to report the occurrence of TEs and associated health care resource utilization and costs among adult patients with PV who were treated with HU in the United States.

\section{Methods}

\section{Study Design and Patients}

In this retrospective cross-sectional analysis, adult patients (aged $\geq 18$ years) with a PV diagnosis (International Classification of Diseases, Ninth Revision, Clinical Modification [ICD-9-CM] code 238.4x) who initiated HU between January 1, 2005, and October 1, 2012, were identified in the Truven Health Analytics MarketScan Research Databases. The index date was defined as the date of the first HU prescription claim. Eligible patients were required to have maintained continuous enrollment in a medical and pharmacy benefit plan for $\geq 12$ months pre-index and $\geq 12$ months post-index. Patients were excluded if they had any of the following during the pre-index period: (a) pharmacy claim for HU; (b) $\geq 2$ nondiagnostic medical claims ( $\geq 30$ days apart) using ICD-9-CM, Current Procedural Terminology, or Healthcare Common Procedure Coding System codes for leukemia (205.1x-3x, 205.8x, 205.9x), myelodysplastic syndrome (238.72-75), or myelofibrosis $(238.76,289.83)$; or (c) any medical claim using ICD-9-CM codes for splenectomy (41.2, 41.43, $41.5,38100-38102,38120)$ or stem cell transplant (41.04-08, 38240-38242, S2142, S2150).

\section{Data Sources}

Two Truven Health Analytics MarketScan Research databases comprising approximately 35 million unique patients annually were used for this analysis. The MarketScan Commercial Claims and Encounters Database contains medical and drug data, predominantly for individuals with employer-sponsored primary health insurance. This database includes fully integrated, deidentified records of real-world patient-level data (e.g., patient demographics, diagnostic information, inpatient admissions, outpatient services, drug claims, and insurance features) for the working population and dependents. The MarketScan Medicare Supplemental Database comprises detailed patient-level medical and drug data for individuals with employer-sponsored Medicare supplemental health insurance. This database encompasses Medicare supplemental and coordination of benefits for retirees covered by their previous employers. Both databases contain a variety of insurance plan types (e.g., preferred provider organization, health maintenance organization, and comprehensive) and benefit design structures.

\section{Assessments}

Patient Demographics and Baseline Disease Characteristics. Patient demographics and baseline characteristics were captured on the index date. The Deyo-Charlson Comorbidity Index Score ${ }^{30}$; patient history of TEs based on ICD-9-CM codes (Table 1); comorbid conditions occurring in $\geq 10 \%$ of patients per ICD9-CM codes; PV-related medications (i.e., interferon- $\alpha 2 a,-\alpha 2 b$, $-\alpha n 3,-a l f a c o n-1,-\beta 1 a,-\beta 1 b, \gamma-1 b$, peginterferon- $\alpha 2 a,-\alpha 2 b$, 


\begin{tabular}{|c|c|}
\hline & $\begin{array}{l}1 \text { ICD-9-CM Codes for TE Diagnosis and } \\
\text { HU-Related Adverse Events }\end{array}$ \\
\hline Code & Description \\
\hline \multicolumn{2}{|c|}{ TE diagnosis } \\
\hline $410 . x x$ & Acute myocardial infarction \\
\hline 411.81 & Acute coronary occlusion without myocardial infarction \\
\hline $415.1 x$ & Pulmonary embolism \\
\hline 433.xx & Occlusion and stenosis \\
\hline $434.0 \mathrm{x}$ & Cerebral thrombosis ${ }^{\mathrm{a}}$ \\
\hline $444 . x x$ & Arterial embolism and thrombosis \\
\hline $445.0 x$ & Atheroembolism \\
\hline $445.8 \mathrm{x}$ & Atheroembolism, other \\
\hline $446.6 x$ & Thrombotic microangiopathy \\
\hline 449.xx & Septic arterial embolism \\
\hline $451 . x x$ & Phlebitis and thrombophlebitis \\
\hline 452.xx & Portal vein thrombosis \\
\hline $453 . x x$ & Other thrombosis \\
\hline \multicolumn{2}{|c|}{ HU-related adverse event } \\
\hline 780.6 & Fever \\
\hline 780.60 & Fever, unspecified \\
\hline 780.61 & Fever presenting with conditions classified elsewhere \\
\hline 780.62 & Postprocedural fever \\
\hline 780.63 & Postvaccination fever \\
\hline 780.66 & Febrile nonhemolytic transfusion reaction \\
\hline 787.91 & Diarrhea \\
\hline 558.2 & Toxic gastroenteritis and colitis \\
\hline 564.5 & Functional diarrhea \\
\hline 787.01 & Nausea with vomiting \\
\hline 787.03 & Vomiting alone \\
\hline 787.04 & Bilious emesis \\
\hline 707.10 & Ulcer of lower limb, unspecified \\
\hline 707.11 & Ulcer of thigh \\
\hline 707.12 & Ulcer of calf \\
\hline 707.13 & Ulcer of ankle \\
\hline 707.14 & Ulcer of heel and midfoot \\
\hline 707.15 & Ulcer of other part of foot \\
\hline 707.19 & Ulcer of other part of lower limb \\
\hline 707.06 & Pressure ulcer, ankle \\
\hline 707.07 & Pressure ulcer, heel \\
\hline \multicolumn{2}{|c|}{$\begin{array}{l}\text { ancluding cerebral thrombosis with cerebral infarction. } \\
H U=\text { hydroxyurea; } I C D-9-C M=\text { International Classification of Diseases, Ninth } \\
\text { Revision, Clinical Modification; TE = thromboembolic event. }\end{array}$} \\
\hline
\end{tabular}

anagrelide, busulfan, JAK inhibitor [ruxolitinib, tofacitinib]) excluding HU; and other classes of concomitant medications (antidepressants [all classes], oral and injectable corticosteroids, prescription nonsteroidal anti-inflammatory drugs [NSAIDs], pneumococcal and varicella virus immunizations, and prescription iron supplements) measured during the 12-month pre-index period were reported.

Hydroxyurea Treatment. Hydroxyurea treatment patterns were reported during the 12-month follow-up period. HU dosing, treatment persistence, treatment adherence, and the most common related adverse events (using prespecified
ICD-9-CM codes; Table 1) were described. Dosing included starting dose, average daily dose, and the minimum and maximum doses during the treatment period. Nonpersistence was defined as a $\geq 45$-day gap in HU therapy using claims data for prescription fills. HU is typically prescribed using a daily dosing regimen that is dispensed to patients with enough medication for 30 days of uninterrupted treatment. The 45-day nonpersistence gap aligns with the International Society for Pharmacoeconomics and Outcomes Research Medication Compliance and Persistence Work Group guidelines for nonpersistence gap determination. ${ }^{31}$ Adherence was evaluated based on medication possession ratio (MPR). MPR was calculated as the number of days of HU supply out of the 12-month follow-up period divided by 365 for patients without an HU treatment gap. For patients with a $\geq 45$-day HU treatment gap, MPR was calculated as the number of days of HU supply divided by the number of days before the first HU discontinuation. Patients were deemed adherent if their MPRs were $\geq 80 \%$.

Thromboembolic Events. Thromboembolic events that occurred during the 12-month follow-up period were identified based on ICD-9-CM diagnosis codes recorded in any place of service and any position on the claim for arterial and venous TEs (Table 1).

Health Care Resource Utilization Costs. All-cause health care resource utilization and associated costs were compared among patients with PV who initiated HU and experienced TEs during the 12-month follow-up period versus those who initiated HU and did not experience TEs during follow-up. Health care resource utilization included inpatient and outpatient services. Inpatient service utilization was characterized by the number of admissions and the average length of stay per admission. Outpatient service utilization was characterized by visits to the emergency room (ER) and physician office, as well as any laboratory and radiology services.

The number of pharmacy claims for any medication and unique medications at the generic product level were summarized for outpatient pharmacy utilization. Total health care costs included inpatient admission costs, outpatient service costs, and outpatient pharmacy costs. Cost for services provided under capitated arrangements were estimated using payment proxies that were computed based on paid claims at the procedure level, using the MarketScan Commercial and Medicare Supplemental Databases. All dollar estimates were inflated to December 2013 dollars using the medical care component of the Consumer Price Index.

\section{Statistical Analyses}

This study consisted of a series of descriptive analyses for PV patients who received HU treatment. Two subanalyses were conducted to compare HU treatment patterns between patients with and patients without $\mathrm{a} \geq 45$-day HU treatment gap and 
Patients with a PV diagnosis between January 1, 2005, and October 1, 2012 with $\geq 1$ nondiagnostic medical claim $\mathrm{N}=75,133$
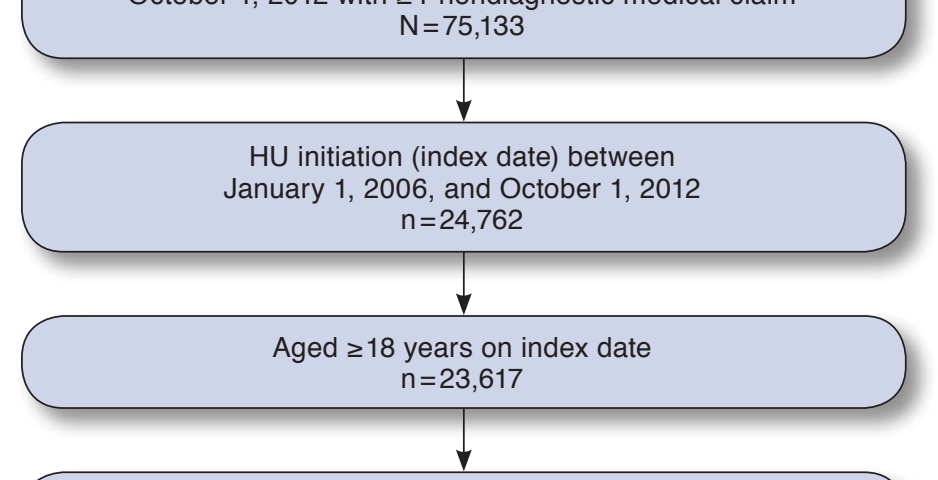

Continuous enrollment in medical/pharmacy benefits for $\geq 6$ months pre-index and $\geq 12$ months post-index $n=10,216$

\section{Excluded patients with:}

- No nondiagnostic medical claim with a PV diagnosis during the pre-index period or on index date

- HU treatment during the pre-index period

- Leukemia, MDS, MF, splenectomy, or stem cell transplant during pre-index period

$$
\mathrm{n}=8,894
$$

Total study sample

$n=1,322$

$\mathrm{HU}=$ hydroxyurea MDS= myelodysplastic syndrome; $M F=$ myelofibrosis; $P V=$ polycythemia vera .

compare health care resource utilization and costs among patients with PV who experienced TEs during follow-up after HU initiation with those who did not.

Categorical variables were presented as the count and percentage of patients in each category; continuous variables were summarized by providing the mean (or median) and standard deviation (SD). Tests for statistically significant differences across the comparison groups were conducted. Chi-square tests were used to evaluate the statistical significance of differences for categorical variables; t-tests were used for continuous variables. A critical value of 0.05 was prespecified as the threshold for statistical significance.

\section{Results}

Patient Demographics and Baseline Disease Characteristics

Of the 75,133 patients who were identified as having PV in the Truven Health Analytics MarketScan Research Databases, 1,322 patients met all inclusion and exclusion criteria and were selected for this study (Figure 1). The mean age at the time of HU initiation was 66 years, with a slightly higher proportion of male patients compared with female patients (Table 2).
One hundred eighty-five patients (14.0\%) had a history of TEs within 1 year before HU initiation. The most frequent comorbidities were hypertension, chronic pain, type 2 diabetes, and anemia. Anagrelide was the most common PV medication received before or at $\mathrm{HU}$ initiation (6.7\%); all others were used by $<1 \%$ of patients (Table 2). The 3 most frequent types of other concomitant medications received before or at HU initiation were antidepressants (18.8\%), corticosteroids (16.5\%), and prescription NSAIDs (13.0\%).

\section{Hydroxyurea Treatment}

The median HU starting dose was $500 \mathrm{mg}$ per day (mg/d) and was the same in patients with or without TEs during followup. Mean (SD) HU starting doses were 728 (384) mg/d for all patients, 763 (442) mg/d for patients who experienced TEs, and 721 (372) $\mathrm{mg} / \mathrm{d}$ for patients who did not experience TEs. Analysis of the dosing range across all patients (500-2,000 mg) indicated that the most frequently prescribed minimum and maximum daily doses of HU were $500 \mathrm{mg}$ (66.3\%) and 1,000 mg (45.1\%), respectively. 


\begin{tabular}{|c|c|c|c|c|c|c|}
\hline \multirow{2}{*}{$\frac{\text { Characteristic }}{\text { Age, years }}$} & \multicolumn{2}{|c|}{$\begin{array}{l}\text { All Patients } \\
(\mathrm{N}=1,322)\end{array}$} & \multicolumn{2}{|c|}{$\begin{array}{c}\text { Patients with TEs During } \\
\text { Follow-up } \\
(\mathrm{n}=216)\end{array}$} & \multicolumn{2}{|c|}{$\begin{array}{c}\text { Patients Without TEs } \\
\text { During Follow-up } \\
(\mathrm{n}=1,106)\end{array}$} \\
\hline & & & & & & \\
\hline Mean (SD) & 66.0 & $(13.3)$ & 66.7 & $(14.8)$ & 65.9 & $(13.0)$ \\
\hline \multicolumn{7}{|l|}{ Sex, n (\%) } \\
\hline Male & 678 & $(51.3)$ & 108 & $(50.0)$ & 570 & $(51.5)$ \\
\hline Female & 644 & $(48.7)$ & 108 & $(50.0)$ & 536 & $(48.5)$ \\
\hline History of thromboembolic event, $\mathrm{n}(\%)^{\mathrm{a}}$ & 185 & $(14.0)$ & 97 & $(44.9)$ & 88 & $(8.0)$ \\
\hline Deyo-Charlson Comorbidity Index score, mean (SD) & 0.79 & $(1.2)$ & 1.1 & $(1.5)$ & 0.7 & $(1.1)$ \\
\hline \multicolumn{7}{|l|}{ Comorbidities, n (\%) } \\
\hline Hypertension & 561 & $(42.4)$ & 110 & $(50.9)$ & 451 & $(40.8)$ \\
\hline Chronic pain & 171 & (12.9) & 38 & $(17.6)$ & 133 & $(12.0)$ \\
\hline Diabetes (type 2) & 156 & $(11.8)$ & 22 & $(10.2)$ & 134 & $(12.1)$ \\
\hline Anemia & 146 & $(11.0)$ & 36 & $(16.7)$ & 110 & $(9.9)$ \\
\hline \multicolumn{7}{|l|}{ Concomitant PV-related medications, n (\%) } \\
\hline Anagrelide & 89 & $(6.7)$ & 14 & $(6.5)$ & 75 & $(6.8)$ \\
\hline Interferon & 9 & $(0.7)$ & 2 & $(0.9)$ & 7 & $(0.6)$ \\
\hline Busulfan & 1 & $(0.1)$ & 0 & $(0.0)$ & 1 & $(0.1)$ \\
\hline JAK inhibitor & 0 & $(0.0)$ & 0 & $(0.0)$ & 0 & $(0.0)$ \\
\hline \multicolumn{7}{|l|}{ Select other concomitant medications, n (\%) } \\
\hline Antidepressants & 248 & (18.8) & 38 & $(17.6)$ & 210 & $(19.0)$ \\
\hline Corticosteroids & 218 & $(16.5)$ & 46 & $(21.3)$ & 172 & $(15.6)$ \\
\hline Prescription NSAIDs & 172 & $(13.0)$ & 25 & $(11.6)$ & 147 & (13.3) \\
\hline Immunizations & 35 & $(2.6)$ & 4 & $(1.9)$ & 31 & $(2.8)$ \\
\hline Prescription iron supplements & 2 & $(0.2)$ & 0 & $(0.0)$ & 2 & $(0.2)$ \\
\hline
\end{tabular}

In total, $764(57.8 \%)$ patients had an HU treatment gap of $\geq 45$ days within the first year of treatment. The mean (SD) HU starting dose was $905(1,375) \mathrm{mg} / \mathrm{d}$ among patients with $\mathrm{a} \geq 45$-day treatment gap and 680 (654) $\mathrm{mg} / \mathrm{d}$ for those without $a \geq 45$-day treatment gap. The mean (SD) number of days from HU initiation to the start of the $\geq 45$-day gap was 135 (99), with $43.3 \%$ of patients reinitiating HU after a mean (SD) of 102 (60) days. Treatment adherence was 85.2\% (mean [SD] MPR, 0.93 [0.11]) and 90.7\% (mean [SD] MPR, 0.94 [0.10]) among patients with versus without $\mathrm{a} \geq 45$-day treatment gap, respectively.

The most common HU-related adverse events during the 12 months of follow-up were gastrointestinal toxicities (6.4\%), fever (4.1\%), and leg ulcers (2.7\%).

\section{Thromboembolic Events}

In total, 216 (16.3\%) patients experienced TEs in the year following HU treatment initiation. Among these, almost half ( $\mathrm{n}=97,44.9 \%$ ) had a documented history of TEs before HU initiation (Table 2). Furthermore, the mean (SD) Deyo-Charlson Comorbidity Index score before HU initiation was higher for patients who developed a TE in the year following initiation of HU treatment (1.1 [1.5]) compared with those who did not (0.7 [1.1]; $P<0.001)$.

\section{Health Care Resource Utilization and Costs}

During the 12-month follow-up period after initiating HU treatment, patients who experienced TEs were significantly more likely to have an inpatient admission or ER visit than those without TEs (inpatient admission, $50.9 \%$ vs. $18.4 \%$, $P<0.001$; ER visit, $48.2 \%$ vs. $26.3 \%, P<0.001$; Table 3). In addition, patients with TEs had a significantly higher mean (SD) number of inpatient admissions (1.7 [1.2] vs. 1.3 [0.7]; $P=0.004)$ and outpatient office visits (18.9 [9.1] vs. 14.1 [7.7]; $P<0.001)$ and received a significantly greater mean (SD) number of prescriptions for any medication compared with those who did not have TEs (45.8 [27.3] vs. 36.2 [25.9], $P<0.001$; Table 3).

Total annual costs were higher among patients who experienced post-index TEs compared with those without TEs. Mean (SD) total annual costs were $\$ 45,040(\$ 106,119)$ and $\$ 16,438$ ( $\$ 27,919)$, respectively $(P<0.001$; Figure 2$)$. Median (interquartile range) annual costs were $\$ 19,859$ $(\$ 10,117-\$ 43,002)$ versus $\$ 8,082(\$ 4,341-\$ 15,837)$. The total annual cost was $>\$ 100,000$ in $9.3 \%$ of patients who had postindex TEs. The difference in total annual costs was driven by significantly higher total inpatient and outpatient costs for 


\begin{tabular}{|c|c|c|c|}
\hline $\begin{array}{l}\text { All-Ca } \\
\text { Utiliz } \\
\text { With }\end{array}$ & $\begin{array}{l}\text { Health Ca } \\
\text { Among } \\
\text { TEs During }\end{array}$ & $\begin{array}{l}\text { e Resource } \\
\text { atients with } \\
\text { 12-Month }\end{array}$ & $\begin{array}{l}\text { and } \\
\text { llow-up }\end{array}$ \\
\hline Health Care Resource & $\begin{array}{l}\text { Patients } \\
\text { with TEs } \\
(\mathrm{n}=216)\end{array}$ & $\begin{array}{c}\text { Patients } \\
\text { Without TEs } \\
(\mathrm{n}=1,106)\end{array}$ & $P$ Value \\
\hline \multicolumn{4}{|l|}{ Inpatient services } \\
\hline Patients, n (\%) & $110(50.9)$ & $203(18.4)$ & $<0.001$ \\
\hline Admissions, mean (SD) & $1.7 \quad(1.2)$ & $1.3 \quad(0.7)$ & 0.004 \\
\hline $\begin{array}{l}\text { Length of stay (days) per } \\
\text { admission, mean (SD) }\end{array}$ & $5.9 \quad(4.1)$ & $6.1 \quad(6.1)$ & 0.753 \\
\hline \multicolumn{4}{|l|}{ Outpatient services } \\
\hline \multicolumn{4}{|l|}{ Emergency room visits } \\
\hline Patients, n (\%) & $104(48.2)$ & $291(26.3)$ & $<0.001$ \\
\hline Visits, mean (SD) & $1.9 \quad(1.4)$ & $1.7 \quad(1.4)$ & 0.347 \\
\hline \multicolumn{4}{|l|}{ Physician office visits } \\
\hline Patients, n (\%) & $214(99.1)$ & $1,095(99.0)$ & 0.925 \\
\hline Visits, mean (SD) & $18.9 \quad(9.1)$ & $14.1 \quad(7.7)$ & $<0.001$ \\
\hline \multicolumn{4}{|l|}{ Outpatient pharmacy services } \\
\hline Patients, $\mathrm{n}(\%)$ & $216 \quad(100)$ & $1,106 \quad(100)$ & 0.990 \\
\hline $\begin{array}{l}\text { Claims for any medication } \\
\text { prescription, mean (SD) }\end{array}$ & $45.8(27.3)$ & $36.2(25.9)$ & $<0.001$ \\
\hline
\end{tabular}

patients with versus those without post-index TEs $(P<0.001$; Figure 2). The average costs associated with individual outpatient services were each significantly higher for patients with TEs, including office visits $(P<0.001)$, ER visits $(P=0.012)$, laboratory and radiology procedures (each $P<0.001$ ), other outpatient services $(P<0.001)$, and outpatient pharmacy costs $(P=0.002)$. During the 12-month follow-up, health plans for all patients receiving HU treatment paid a mean (SD) of $\$ 19,448$ $(\$ 50,483)$ for all-cause health care costs, compared with $\$ 1,672(\$ 1,428)$ that was paid out-of-pocket by the patients. Health plans paid the majority of costs for patients who did and did not experience post-index TEs: $\$ 42,734(\$ 105,520)$ and $\$ 14,889$ ( $\$ 27,452)$, respectively. Corresponding values for patient out-of-pocket costs were $\$ 2,306(\$ 1,859)$ and $\$ 1,549$ $(\$ 1,293)$, respectively.

\section{Discussion}

The National Comprehensive Cancer Network and European LeukemiaNet treatment guidelines recommend HU as firstline cytoreductive medication for patients with $\mathrm{PV},{ }^{27,32}$ based on clinical studies indicating an association with increased survival and reduced thromboembolic risk. ${ }^{28,33}$ This retrospective analysis of data from 2 Truven Health Analytics MarketScan Research databases suggests that nearly 1 in 6 patients with PV experienced a TE within the first year after initiating HU treatment, the occurrence of which is associated with increased health care resource utilization and costs. Indeed, only $44.9 \%$ of the patients with TEs during the 1-year follow-up had a history of TEs before HU initiation, suggesting that patients with PV could develop new TEs despite being treated with HU.

The patient demographics in this analysis were similar to those described in the current literature, including mean age between 60 and 69 years and a slightly higher predominance of men versus women. ${ }^{34-37}$ The HU discontinuation rate in the current study was notably high, which may place patients at a higher risk for TEs. Nearly $60 \%$ of patients discontinued treatment and were nonpersistent (defined as a $\geq 45$-day treatment gap) within the first year of treatment initiation. In comparison, a retrospective study of 1,309 patients with PV reported that $17.5 \%$ discontinued $\mathrm{HU}$, with a mean treatment duration of 23.2 months. ${ }^{38}$ Based on the limitations inherent to this claims database analysis, the specific reasons that led to patient discontinuation of HU are unknown. Despite the high discontinuation rate, patients were generally considered treatment adherent through the first year following HU initiation or up to the point of discontinuation, and the daily HU dose was between 500 and 1,000 mg for most patients, consistent with real-world practice. ${ }^{38}$

The rate of TEs in our analysis (16.3\%) was comparable with findings from a retrospective international study of patients with PV ( $\mathrm{n}=1,545)$, which reported incidences of arterial thrombosis, venous thrombosis, and major hemorrhage at $12 \%, 9 \%$, and $4.2 \%$, respectively. ${ }^{39}$ However, the proportion of patients receiving HU was only approximately 60\%, and the median follow-up period was 6.9 years, which precludes meaningful comparisons with our analysis.

The current study is novel because, to our knowledge, it is the first to demonstrate that the occurrence of TEs in patients with PV is associated with higher health care resource utilization and costs, despite treatment with HU. A previous retrospective cohort study of U.S. commercial plans reported higher 12-month overall costs among patients with PV who experienced TEs versus those who did not $(\$ 48,211$ vs. $\$ 10,958)$ or received treatment with $\mathrm{HU}$ versus those who did not $(\$ 7,657$ vs. $\$ 2,535)$. However, the analysis did not include data focused on HU-treated patients who experienced TEs. ${ }^{40}$

In our analysis, health care resource utilization in inpatient and outpatient settings was higher for patients treated with HU who experienced TEs within the first year compared with those who did not. The proportion of patients who had TEs and required ER and inpatient visits were 2 to 3 times that of patients who did not have TEs. In addition, patients with TEs had approximately 30\% more outpatient visits and claims for prescriptions. As a result, total annual all-cause health care costs among patients who experienced TEs within the first year of HU treatment were nearly 3 times the costs among patients who did not, and total inpatient costs were 4 times as much. The resulting elevated annual costs associated with TEs in this study were consistent with the TE-associated health care 


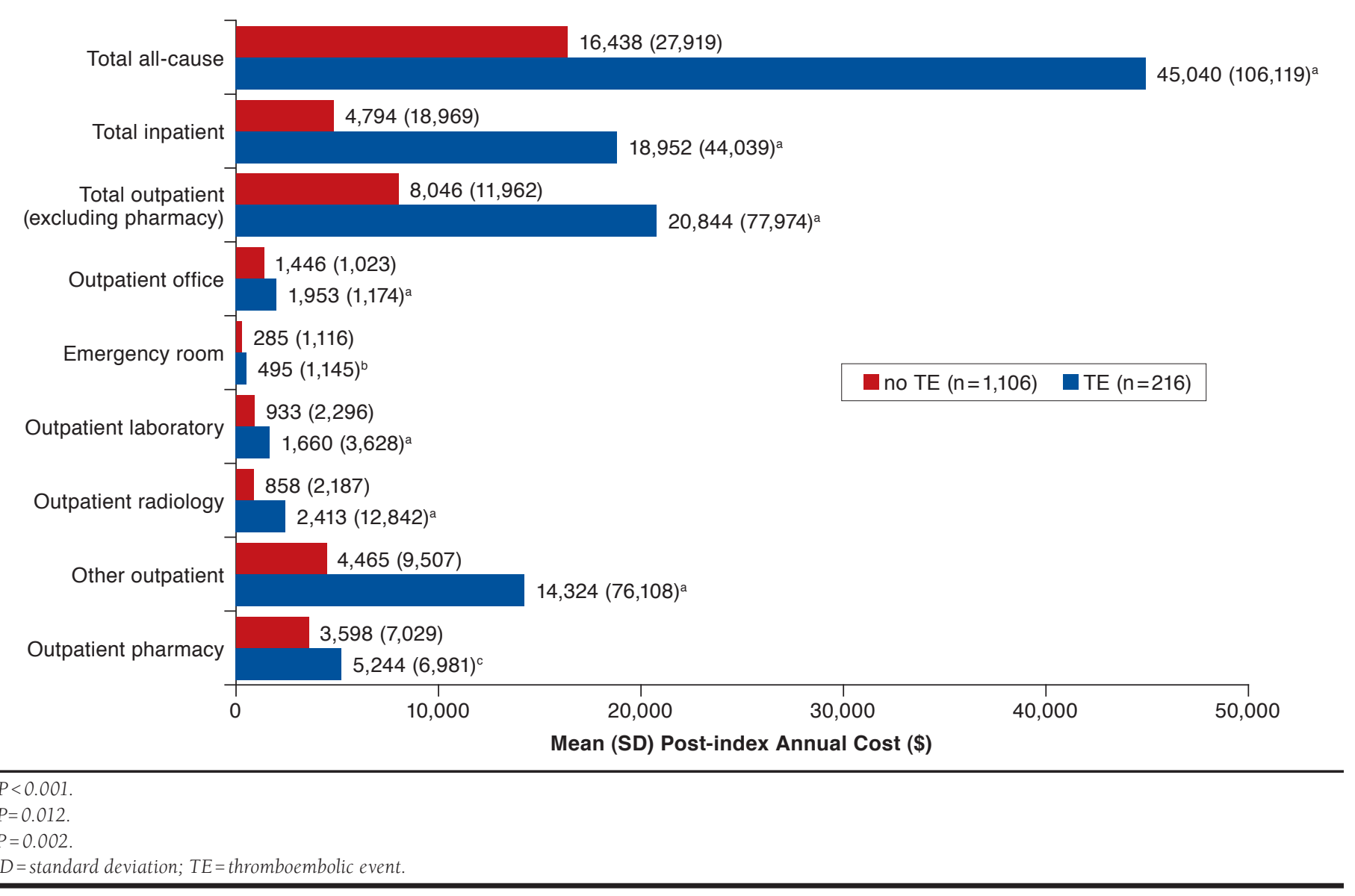

costs in the United States $(\$ 18,300-\$ 55,500) .{ }^{20,41}$ These elevated costs represent a considerable economic burden from a societal perspective when compared with the median U.S. household income between 2006 and 2012 (\$48,201-\$51,017). ${ }^{42-48}$ In addition, the elevated mean direct medical costs (excluding indirect costs such as lost productivity) resulting from TEs paid out of pocket by patients represent nearly $10 \%$ of median income.

The continued occurrence of TEs in patients with PV treated with HU reported here is consistent with interim results from the ongoing multicenter Prospective Observational Study of Patients With Polycythemia Vera in U.S. Clinical Practices (REVEAL), which showed that patients with PV experienced TEs before and after the PV diagnosis, emphasizing a need for better patient management to prevent such events. ${ }^{49}$ The majority of patients were being actively managed at enrollment, and HU was part of the treatment plan in a large proportion of the early-enrolled patient cohort. ${ }^{49}$ Future analyses of REVEAL following full patient enrollment will provide important insights into real-world PV-related burdens, including cardiovascular and TE risk and health care resource utilization, across a broad segment of the PV population. ${ }^{49}$

\section{Limitations}

Limitations of this study are primarily related to those inherent to cross-sectional claims database analyses. In the absence of the actual medical records, this study assumes that claims were accurately coded and that patients identified with PV and TEs represent true positive cases. Furthermore, the full history of each TE was unknown; some TE-coded claims may have been related to events that first occurred before the index date, and patients were not followed for equal amounts of time after each event. HU treatment persistence and adherence were assessed and reported solely based on insurance claim data; actual drug use by the patients was not confirmed.

The actual costs associated with TEs may be underreported in the current analysis because of incomplete documentation of clinical characteristics and history of over-the-counter medications, such as low-dose aspirin. This study analyzed 
privately insured and Medicare supplement patients so is not generalizable to patients who are uninsured or those covered under standard Medicare plans, Medicaid, or other government insurance programs.

Finally, the current analysis focused exclusively on direct medical costs incurred during the first year after HU initiation and, because of database limitations, did not include indirect costs or costs associated with downstream events, such as disability, loss of productivity, impaired quality of life, rehabilitation, and subsequent TEs beyond the first year. A future analysis of these costs is warranted to evaluate the comprehensive societal burden associated with TEs among patients with PV treated with HU.

\section{Conclusions}

The results of this retrospective analysis of 1,322 patients suggest that despite treatment with $\mathrm{HU}, 16.3 \%$ of patients with PV experienced TEs within the first year of therapy. Furthermore, patients who experienced TEs had significantly higher health care resource utilization and costs during follow-up compared with patients who did not experience TEs. These findings support the regular assessment of patients with PV for signs of inadequate disease control and the identification of those at increased risk of developing TEs to ensure that appropriate therapy is initiated accordingly. Further analyses will be required to determine the types and frequency of assessments that are effective for the reduction of TE risk in patients with PV and the corresponding health care resource utilization and costs.

\section{Authors}

SHREEKANT V. PARASURAMAN, BPharm, PhD, and DILAN C. PARANAGAMA, PhD, Incyte Corporation, Wilmington, Delaware. NIANWEN SHI, PhD, and MACHAON BONAFEDE, PhD, MPH, Truven Health Analytics, Cambridge, Massachusetts.

AUTHOR CORRESPONDENCE: Shreekant V. Parasuraman, BPharm, PhD, Incyte Corporation, 1801 Augustine Cut-Off, Wilmington, DE 19803. Tel.: 302.498.5785; E-mail: sparasuraman@incyte.com.

\section{ACKNOWLEDGMENTS}

Writing assistance was provided by Phuong Tran, PharmD (Complete Healthcare Communications, West Chester, PA, a CHC Group company) and was funded by Incyte Corporation.

\section{REFERENCES}

1. Arber DA, Orazi A, Hasserjian R, et al. The 2016 revision to the World Health Organization classification of myeloid neoplasms and acute leukemia. Blood. 2016;127(20):2391-405.

2. Passamonti F, Rumi E, Pietra D, et al. A prospective study of 338 patients with polycythemia vera: the impact of JAK2 (V617F) allele burden and leukocytosis on fibrotic or leukemic disease transformation and vascular complications. Leukemia. 2010;24(9):1574-79.

3. Pasquier F, Cabagnols X, Secardin L, Plo I, Vainchenker W. Myeloproliferative neoplasms: JAK2 signaling pathway as a central target for therapy. Clin Lymphoma Myeloma Leuk. 2014;14(Suppl):S23-35.

4. Milosevic JD, Kralovics R. Genetic and epigenetic alterations of myeloproliferative disorders. Int J Hematol. 2013;97(2):183-97.

5. Mehta J, Wang H, Iqbal SU, Mesa R. Epidemiology of myeloproliferative neoplasms in the United States. Leuk Lymphoma. 2014;55(3):595-600.

6. Stein BL, Moliterno AR, Tiu RV. Polycythemia vera disease burden: contributing factors, impact on quality of life, and emerging treatment options. Ann Hematol. 2014:93(12):1965-76.

7. Hultcrantz M, Kristinsson SY, Andersson TM, et al. Patterns of survival among patients with myeloproliferative neoplasms diagnosed in Sweden from 1973 to 2008: a population-based study. J Clin Oncol. 2012;30(24):2995-3001

8. Price GL, Davis KL, Karve S, Pohl G, Walgren RA. Survival patterns in United States (U.S.) Medicare enrollees with non-CML myeloproliferative neoplasms (MPN). PLoS ONE. 2014;9(3):e90299.

9. Marchioli R, Finazzi G, Landolfi R, et al. Vascular and neoplastic risk in a large cohort of patients with polycythemia vera. J Clin Oncol. 2005;23(10):2224-32

10. Hultcrantz M, Andersson TM-L, Landgren O, et al. Risk of arterial and venous thrombosis in 11,155 patients with myeloproliferative neoplasms and 44,620 matched controls; a population-based study. Blood. 2014;124(21):632 [Abstract]. Available at: http://www.bloodjournal.org/ content/124/21/632?sso-checked=true. Accessed November 27, 2017.

11. Kaifie A, Kirschner M, Wolf D, et al. Bleeding, thrombosis, and anticoagulation in myeloproliferative neoplasms (MPN): analysis from the German SAL-MPN-registry. J Hematol Oncol. 2016;9(1):18.

12. Marchioli R, Finazzi G, Specchia G, et al. Cardiovascular events and intensity of treatment in polycythemia vera. N Engl J Med. 2013;368(1):22-33. 13. Barbui T, Masciulli A, Marfisi MR, et al. White blood cell counts and thrombosis in polycythemia vera: a subanalysis of the CYTO-PV study. Blood. 2015;126(4):560-61.

14. Vannucchi AM, Antonioli E, Guglielmelli P, et al. Prospective identification of high-risk polycythemia vera patients based on JAK2(V617F) allele burden. Leukemia. 2007:21(9):1952-59.

15. Mesa R, Miller CB, Thyne M, et al. Myeloproliferative neoplasms (MPNs) have a significant impact on patients' overall health and productivity: the MPN Landmark survey. BMC Cancer. 2016;16:167.

16. Mehta J, Wang H, Fryzek JP, Iqbal SU, Mesa R. Health resource utilization and cost associated with myeloproliferative neoplasms in a large United States health plan. Leuk Lymphoma. 2014;55(10):2368-74.

17. Zhang Z, Kolm P, Mosse F, Jackson J, Zhao L, Weintraub WS. Longterm cost-effectiveness of clopidogrel in STEMI patients. Int J Cardiol. 2009;135(3):353-60.

18. Mahoney EM, Mehta S, Yuan Y, et al. Long-term cost-effectiveness of early and sustained clopidogrel therapy for up to 1 year in patients undergoing percutaneous coronary intervention after presenting with acute coronary syndromes without ST-segment elevation. Am Heart J. 2006;151(1):219-27. 
19. Weintraub WS, Mahoney EM, Lamy A, et al. Long-term cost-effectiveness of clopidogrel given for up to one year in patients with acute coronary syndromes without ST-segment elevation. J Am Coll Cardiol. 2005;45(6):838-45. 20. O'Sullivan AK, Rubin J, Nyambose J, Kuznik A, Cohen DJ, Thompson D. Cost estimation of cardiovascular disease events in the U.S. Pharmacoeconomics. 2011;29(8):693-704.

21. Nichols GA, Bell TJ, Pedula KL, O'Keeffe-Rosetti M. Medical care costs among patients with established cardiovascular disease. Am J Manag Care. 2010;16(3):e86-e93.

22. Sculpher MJ, Lozano-Ortega G, Sambrook J, et al. Fondaparinux versus enoxaparin in non-ST-elevation acute coronary syndromes: short-term cost and long-term cost-effectiveness using data from the Fifth Organization to Assess Strategies in Acute Ischemic Syndromes Investigators (OASIS-5) trial. Am Heart J. 2009; 157(5):845-52.

23. Lefebvre P, Coleman CI, Bookhart BK, et al. Cost-effectiveness of rivaroxaban compared with enoxaparin plus a vitamin $\mathrm{K}$ antagonist for the treatment of venous thromboembolism. J Med Econ. 2014;17(1):52-64.

24. Lefebvre P, Laliberté F, Nutescu EA, et al. All-cause and potentially disease-related health care costs associated with venous thromboembolism in commercial, Medicare, and Medicaid beneficiaries. J Manag Care Pharm. 2012;18(5):363-74. Available at: http://www.jmcp.org/doi/10.18553/ jmcp.2012.18.5.363.

25. Vannucchi AM. How I treat polycythemia vera. Blood. 2014; 124(22):3212-20

26. Landolfi R, Marchioli R, Kutti J, et al. Efficacy and safety of low-dose aspirin in polycythemia vera. N Engl J Med. 2004;350(2):114-24.

27. Barbui T, Barosi G, Birgegard G, et al. Philadelphia-negative classical myeloproliferative neoplasms: critical concepts and management recommendations from European LeukemiaNet. J Clin Oncol. 2011;29(6):761-70.

28. Kiladjian JJ, Chevret S, Dosquet C, Chomienne C, Rain JD. Treatment of polycythemia vera with hydroxyurea and pipobroman: final results of a randomized trial initiated in 1980. J Clin Oncol. 2011;29(29):3907-13.

29. Alvarez-Lárran A, Pereira A, Cervantes F, et al. Assessment and prognostic value of the European LeukemiaNet criteria for clinicohematologic response, resistance, and intolerance to hydroxyurea in polycythemia vera. Blood. 2012;119(6):1363-69.

30. Deyo RA, Cherkin DC, Ciol MA. Adapting a clinical comorbidity index for use with ICD-9-CM administrative databases. J Clin Epidemiol. 1992;45(6):613-19.

31. Cramer JA, Roy A, Burrell A, et al. Medication compliance and persistence: terminology and definitions. Value Health. 2008;11(1):44-47.

32. National Comprehensive Cancer Network. NCCN Clinical Practice Guidelines in Oncology. Myoproliferative neoplasms v.1.2018. Available at: https://www.nccn.org/professionals/physician_gls/default.aspx\#site. Accessed November 27, 2017.

33. Fruchtman SM, Mack K, Kaplan ME, Peterson P, Berk PD, Wasserman LR. From efficacy to safety: a Polycythemia Vera Study Group report on hydroxyurea in patients with polycythemia vera. Semin Hematol. 1997;34(1):17-23

34. Vannucchi AM, Antonioli E, Guglielmelli P, et al. Clinical profile of homozygous JAK2 $617 \mathrm{~V}>\mathrm{F}$ mutation in patients with polycythemia vera or essential thrombocythemia. Blood. 2007;110(3):840-46.

35. Johansson P, Mesa R, Scherber R, et al. Association between quality of life and clinical parameters in patients with myeloproliferative neoplasms. Leuk Lymphoma. 2012;53(3):441-44.
36. Emanuel RM, Dueck AC, Geyer HL, et al. Myeloproliferative Neoplasm (MPN) Symptom Assessment Form Total Symptom Score: prospective international assessment of an abbreviated symptom burden scoring system among patients with MPNs. J Clin Oncol. 2012;30(33):4098-103.

37. Abelsson J, Andreasson B, Samuelsson J, et al. Patients with polycythemia vera have the worst impairment of quality of life among patients with newly diagnosed myeloproliferative neoplasms. Leuk Lymphoma. 2013;54(10):2226-30.

38. Parasuraman S, DiBonaventura M, Reith K, Naim A, Concialdi K, Sarlis NJ. Patterns of hydroxyurea use and clinical outcomes among patients with polycythemia vera in real-world clinical practice: a chart review. Exp Hematol Oncol. 2016;5:3.

39. Tefferi A, Rumi E, Finazzi G, et al. Survival and prognosis among 1545 patients with contemporary polycythemia vera: an international study. Leukemia. 2013;27(9):1874-81.

40. Goyal RK, Davis KL, Cote I, Mounedji N, Kaye JA. Health care resource use and costs among polycythemia vera patients in the United States: results from an observational cohort study. Value Health. 2015;18(7):A482-83 [Abstract PCN297]. Available at: http://www.valueinhealthjournal.com/ article/S1098-3015(15)03392-6/abstract. Accessed November 27, 2017. 41. Mahan CE, Borrego ME, Woersching AL, et al. Venous thromboembolism: annualised United States models for total, hospital-acquired and preventable costs utilising long-term attack rates. Thromb Haemost. 2012;108(2):291-302.

42. DeNavas-Walt C, Proctor BD, Smith JC. Income, poverty, and health insurance coverage in the United States: 2012. U.S. Census Bureau. September 2013. Available at: https://www.census.gov/prod/2013pubs/p60245.pdf. Accessed November 27, 2017.

43. DeNavas-Walt C, Proctor BD, Smith JC. Income, poverty, and health insurance coverage in the United States: 2011. U.S. Census Bureau. September 2012. Available at: https://www.census.gov/prod/2012pubs/p60243.pdf. Accessed November 27, 2017.

44. DeNavas-Walt C, Proctor BD, Smith JC. Income, poverty, and health insurance coverage in the United States: 2010. U.S. Census Bureau. September 2011. Available at: http://www.census.gov/prod/201lpubs/p60239.pdf. Accessed November 27, 2017.

45. DeNavas-Walt C, Proctor BD, Smith JC. Income, poverty, and health insurance coverage in the United States: 2009. U.S. Census Bureau. September 2010. Available at: https://www.census.gov/prod/2010pubs/p60238.pdf. Accessed November 27, 2017.

46. DeNavas-Walt C, Proctor BD, Smith JC. Income, poverty, and health insurance coverage in the United States: 2008. U.S. Census Bureau. September 2009. Available at: https://www.census.gov/prod/2009pubs/p60236.pdf. Accessed November 27, 2017

47. DeNavas-Walt C, Proctor BD, Smith JC. Income, poverty, and health insurance coverage in the United States: 2007. U.S. Census Bureau. August 2008. Available at: https://www.census.gov/prod/2008pubs/p60-235. pdf. Accessed November 27, 2017.

48. DeNavas-Walt C, Proctor BD, Smith JC. Income, poverty, and health insurance coverage in the United States: 2006. U.S. Census Bureau. August 2007. Available at: https://www.census.gov/prod/2007pubs/p60-233.pdf. Accessed November 27, 2017.

49. Stein B, Moliterno A, Boccia RV, et al. Disease and clinical characteristics of patients with polycythemia vera: an early view of the REVEAL study. Blood. 2015;126(23):2813 [Abstract]. Available at: http://www.bloodjournal. org/content/126/23/2813?utm_source=TrendMD\&utm_medium=cpc\&utm_ campaign=Blood_TrendMD_0\&sso-checked=true. Accessed November 27, 2017. 